\title{
Lessons of Epidemiology of Diabetes
}

\author{
R. J. JARRETT,* M.A., M.D.
}

British Medical fournal, 1970, 3, 270-271

One of the trends in medicine since the second world war has been the emphasis placed on the early or presymptomatic diagnosis of disease. Those interested in diabetes, if not the leaders in the field, have probably tilled it more than most, with diabetic detection drives, academically more respectable population surveys, and screening of selected groups becoming ever more popular. The resultant of all these has been a lot more diabetics, much information about the nature and aetiology of diabetes, and its relation to other disorders, but, as yet, little of immediate clinical importance.

\section{What is Diabetes?}

Perhaps the most important outcome of the epidemiological approach to diabetes has been a change in the concept of the disease. From classical times, diabetes has been recognized as an acute disorder, presenting with copious micturition (the "pissing evil" in Thomas Willis's graphic terms), wasting, and thirst, progressing eventually to coma and death. The advent of insulin therapy altered the natural history of this in a dramatic fashion. The twentieth century has seen the rise of that variety of diabetes sometimes called "maturity" or "adult" onset, more properly called "non-insulin dependent" and of ten referred to, most improperly, as "mild". This variety now outnumbers the insulin dependent by 4 or 5 to 1 , and in about half of these diabetics the diagnosis has been made incidentally, urine having been examined during some routine examination. Many are truly asymptomatic, even on direct questioning. Despite this, diagnosis of the diabetes is not usually difficult, for random or postglucose blood sugar levels are sufficiently high to allow of no doubt. Nevertheless, when screening by blood sugar level is employed for case finding, diagnosis becomes more problematic.

Oral glucose tolerance tests performed on several normal population samples have shown that there is no obvious division between the clearly normal people at one end of the spectrum of distribution and the clearly diabetic people at the other. ${ }^{1}$ Furthermore, the oral glucose tolerance test itself has had its imperfections exposed-though it remains the best single test that we possess. G. W. McDonald and his coworkers ${ }^{2}$ have performed repeated tests over a period of a year on many people and have shown that there is considerable variation in an individual's results from time to time; some people actually swung from "normal" to "diabetic" and back again over the course of six tests. J. B. O'Sullivan and D. Hurwitz ${ }^{3}$ followed up a group of women diagnosed as diabetic during periodic glucose tolerance testing, using the fairly strict United States Public Health Service criteria for the diagnosis. They found that many remitted without treatment over the succeeding years. It has been a general experience that mean blood sugar levels, following a glucose load, rise with age. ${ }^{1}$ This phenomenon raises the problem of whether the same criteria of normality should be applied across the age range or whether they should be "ageadjusted". In practical terms one would take a different view of moderate hyperglycaemia in a 30 year old compared with an octogenarian, but the philosophical question remains

* Lecturer, Department of Medicine, Guy's Hospital, London S.E.1. unanswered. A new twist to the oral glucose tolerance test has been the finding that performing the test in the afternoon leads, in general, to higher post-glucose blood sugar levels and that, in many people with normal morning tests afternoon blood sugars lie in the conventionally diabetic range. ${ }^{4}$ Are these people diabetic? Or are they people with impaired glucose homoeostasis forming a reservoir of potential diabetics? Is the difference quantitative or qualitative?

Whatever the answer to these questions may be, clearly the term "diabetes" has lost its hard edge and any comprehensive definition of diabetes has to be in terms of levels of blood sugar. No doubt we shall retain the ancient descriptive term for many years to come, but in doing so we should remember its limitations.

\section{Prevalence of Diabetes}

For the reasons discussed above, the true prevalence of diabetes is impossible to discover-any estimates will be influenced by the criteria adopted for diagnosis. Furthermore, there have been few truly representative population samples examined, most studies having employed some sort of initial screening procedure involving urine tests for glucose. This is now known to lead to over-representation of the young and under-representation of the old in the second stage of screening. This is because the renal "threshold" for glucose rises with age, so that a young person may have glucosuria with normoglycaemia while an older person has hyperglycaemia, but is aglucosuric. ${ }^{5}$ Nevertheless, estimates of prevalence in Europe, Australasia, and North America are similar, being about 2 to $10 \%$ of the total population, the range being due predominantly to differences in diagnostic criteria rather than in prevalence. The bulk of the diabetic population lies in the over 50 s.

There are groups, however, in which prevalence is certainly much higher or lower than this. In the lower category are the Eskimoes of Alaska and Greenland and the Alaskan Athabaskan Indians, who have relatively low levels of blood sugar in glucose tolerance tests and a very low prevalence of diabetes of any kind.$^{6}$ In contrast, certain other American Indian tribes show a much higher prevalence of diabetes than the general population, among them the Pima, Seneca, Cherokee, and Cocopah. The Pima head the world league table with a prevalence exceeding $40 \%$ among men aged 35 and above.

Some other racial differences have been found. In Trinidad the prevalence of diabetes was found to be higher in those of East Indian origin compared with those of African origin. ${ }^{7}$ Similarly, in South Africa the prevalence of diabetes was greater among Indians than among Africans or Europeans of similar urban areas ${ }^{8}$.

Several epidemiological studies have pointed to the importance of environment in determining the prevalence of diabetes. Thus in Israel no difference was found among Jews immigrating from various parts of the world, except for Kurds and Yemenites. ${ }^{9}$ In these two groups diabetes was much less common in new immigrants compared with those who had lived in Israel for 25 years or more. Among the 
Maoris of New Zealand diabetes is much more frequent than among the racially similar inhabitants of the Cook Islands, whose caloric intake is less and who also have a lesser prevalence of obesity. ${ }^{10} \mathrm{~K}$. M. West and J. M. Kalbfleisch ${ }^{11}$ studied the prevalence of diabetes in population samples in Uruguay, Venezuela, Malaya, and East Pakistan, using the same procedures in each. In people over the age of 30 the respective prevalences were $6.9 \%, 7.3 \%, 3.5 \%$, and $1.5 \%$. Several other variables correlated with the prevalence of diabetes; but the authors were most impressed by the consistent relation between an excess of calories in relation to energy expenditure and the prevalence of diabetes, regardless of the source of the calories.

The other major factor in diabetes prevalence is heredity and views have gradually changed about its nature and importance. It is generally held now that the inheritance of diabetes is multifactorial; there is still controversy about the possible differences in the inheritance of juvenile compared with maturity onset diabetes. The relative importance of heredity has been illuminated by two studies-one British ${ }^{12}$ and one American ${ }^{13}$ - of the offspring of conjugal diabetics (both parents diabetic). In both studies the estimated number of children likely to become overtly diabetic if all lived to 85 years was less than $30 \%$

\section{Diabetes and Atherosclerosis}

It has long been held that diabetics are relatively more prone to atherosclerosis, especially ischaemic heart disease and peripheral vascular disease. This, in particular the enhanced risk of the diabetic woman compared with her non-diabetic counterpart, is now beyond doubt. Nevertheless, population studies have uncovered a significant association between moderate degrees of hyperglycaemia after a glucose load and increased prevalence of such vascular disease. Follow-up studies on these populations have confirmed the association by showing an increased incidence of new disease in those with moderate hyperglycaemia, sometimes called "borderline" diabetics. Thus hyperglycaemia joins hypercholesterolaemia, obesity, and hypertension as a risk factor in the development of atherosclerosis vascular disease. ${ }^{14}$ This brings back the subject of presymptomatic diagnosis and the potential benefits of treatment. At present, as with all these risk factors, it is not clear who should be treated, by what means, or what degree of benefit may be expected. Several controlled trials are in progress and some encouraging results with tolbutamide treatment of "borderline" diabetics has been reported, ${ }^{15}$ but it will be some time before the revelations of the epidemiologists yield firm clinical indications about treatment.

REFERENCES

1 Gordon, T., Vital and Health Statistics, Series 11, No. 2, 1964.

2 McDonald, G. W., Fisher, G. F., and Burnham, C., Diabetes, 1965, 14, 473.

${ }^{3}$ O'Sullivan, J. B., and Hurwitz, D., Archives of Internal Medicine, 1966, 117,769 .
Jarrett, R. J., and Keen, H., British Medical fournal, 1969, 2, 341 and (1970) Unpublished results.

${ }^{5}$ Butterfield, W. J. H., Keen, H., and Whichelow, M. J., British Medical fournal, 1967, 4, 505.

- Pyke, D. A., Postgraduate Medical Fournal, 1969, 45, 796.

? Poon-King, T., Henry, M. V., and Rampersad, F., Lancet, 1968, 1, 155.

8 Marine, N., Vinik, A. I., Edelstein, I., and Jackson, W. P. U., Diabetes, $1969,18,840$.

9 Cohen, A. M., Metabolism, 1961, 10, 50

Wellington Hospital, New Zealand. Department of Health. Special Report Series, No. 26, 1966.

1 West, K. M., and Kalbfleisch, J. M., Diabetes, 1966, 15, 9.

12 Cooke, A. M., Fitzgerald, M. G., Malins, J. M., and Pyke, D. A., British Medical fournal, 1966, 2, 674

13 Kahn, C. B., et al., New England Fournal of Medicine, 1969, 281, 343.

14 Epstein, F. H., Circulation, 1967, 36, 609.

15 Keen, H., Jarrett, R. J., Chlouverakis, C., and Boyns, D. R., Postgraduate Medical fournal, 1968, 44, 960 .

16 Lacy, P. E., and Kostianovsky, M., Diabetes, 1967, 16, 35.

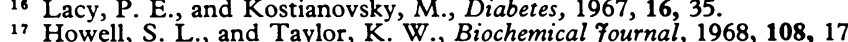

17 Howell, S. L., and Taylor, K. W., Biochemical fournal, 1968

19 Malaisse, W. J., Malaisse-Lagae, F., and Wright, P. H., Endocrinology $1967,80,99$.

20 Montague, W., and Taylor, K. W., Biochemical Fournal, 1969, 115, 257

21 Sutherland, E. W., and Robison, G. A., Diabetes, 1969, 18, 797

22 Steiner, D. F., et al., Recent Progress Hormone Research, 1969, 25, 207.

23 Porte, D., Graber, A. L., Kuzuya, T., and Williams, R. H., fournal of Clinical Investigation, 1966, 45, 228.

24 Taylor, K. W., in Hormones in Blood, ed. C. H. Gray, vol. 1, p. 47. London, Academic Press, 1967.

25 Unger, R. H., Aguilar-Parada, E., Müller, W. A., and Eisentraut, A. M., fournal of Clinical Investigation, 1970, 49, 837.

26 Gamble, D. R., et al., British Medical fournal, 1969, 3, 627

26 Gamble, D. R., et al., British Medical fournal, 1969, 3, 627.

28 Perley, M. J., and Kipnis, D. M., Fournal of Clinical Investigation, 1967, 46, 1954.

29 Hales, C. N., and Kennedy, G. C., Biochemical fournal, 1964, 90, 620.

30 Mayer, J., American fournal of Clinical Nutrition, 1960, 8, 712.

31 Vallance-Owen, J., Ciba Foundation Colloquia in Endocrinology, 1964, 15, 217.

32 Randle, P. J., Garland, P. B., Newsholme, E. A., and Hales, C. N., Annals of New York Academy of Sciences, 1965, 131, 324.

33 Young, F. G., Lancet, 1937, 2, 372.

34 Campbell, J., and Rastogi, K. S., Diabetes, 1966, 15, 749.

35 Cerasi, E., and Luft, R., Acta Endocrinologica (Kobenhavn), 1967, 55, 278.

36 Pyke, D. A., and Taylor, K. W., British Medical fournal, 1967, 4, 21.

37 Pyke, D. A., Cassar, J., and Taylor, K. W. (in preparation).

38 Guardian, 22 May 1970

39 Oakley, W. G., Pyke, D. A., and Taylor, K. W., Clinical Diabetes and it Biochemical Basis. Oxford, Blackwell, 1968.

40 Pyke, D. A., Fournal of Clinical Pathology, 1969, 22, suppl. (Ass. Clin. Path.), 2, 57.

11 Watkins, P. J., Smith, J. S., FitzGerald, M. G., and Malins, J. M., British Medical fournal, 1969, 1, 744.

\section{B. M.J. Publications}

The following are available from the Publishing Manager, B.M.A. House, Tavistock Square, London, WC1H 9JR. The prices include postage.

Today's Drugs/1 (New Series)

Price 20s.

Road Accidents and the Family Doctor

The New General Practice

Price 10s.

Diseases of the Digestive System

Price 16s.

B.M.f. Annual Cumulative Index, $1967,68,69$

Price 40s.

Price 30s. each (15s. to B.M.A. Members) 